Q. XIAO, J. J. JACKSON, A. BASAK, J. M. BOWLER, B. G. MILLER,* A. ZAKARIAN* (UNIVERSITY OF CALIFORNIA, SANTA BARBARA AND FLORIDA STATE UNIVERSITY, TALLAHASSEE, USA)

Enantioselective Synthesis of Tatanans A-C and Reinvestigation of Their Glucokinase-Activating Properties Nature Chem. 2013, 5, 410-416.

\section{Synthesis of Tatanans A-C and Their Glucokinase-Activating Properties}

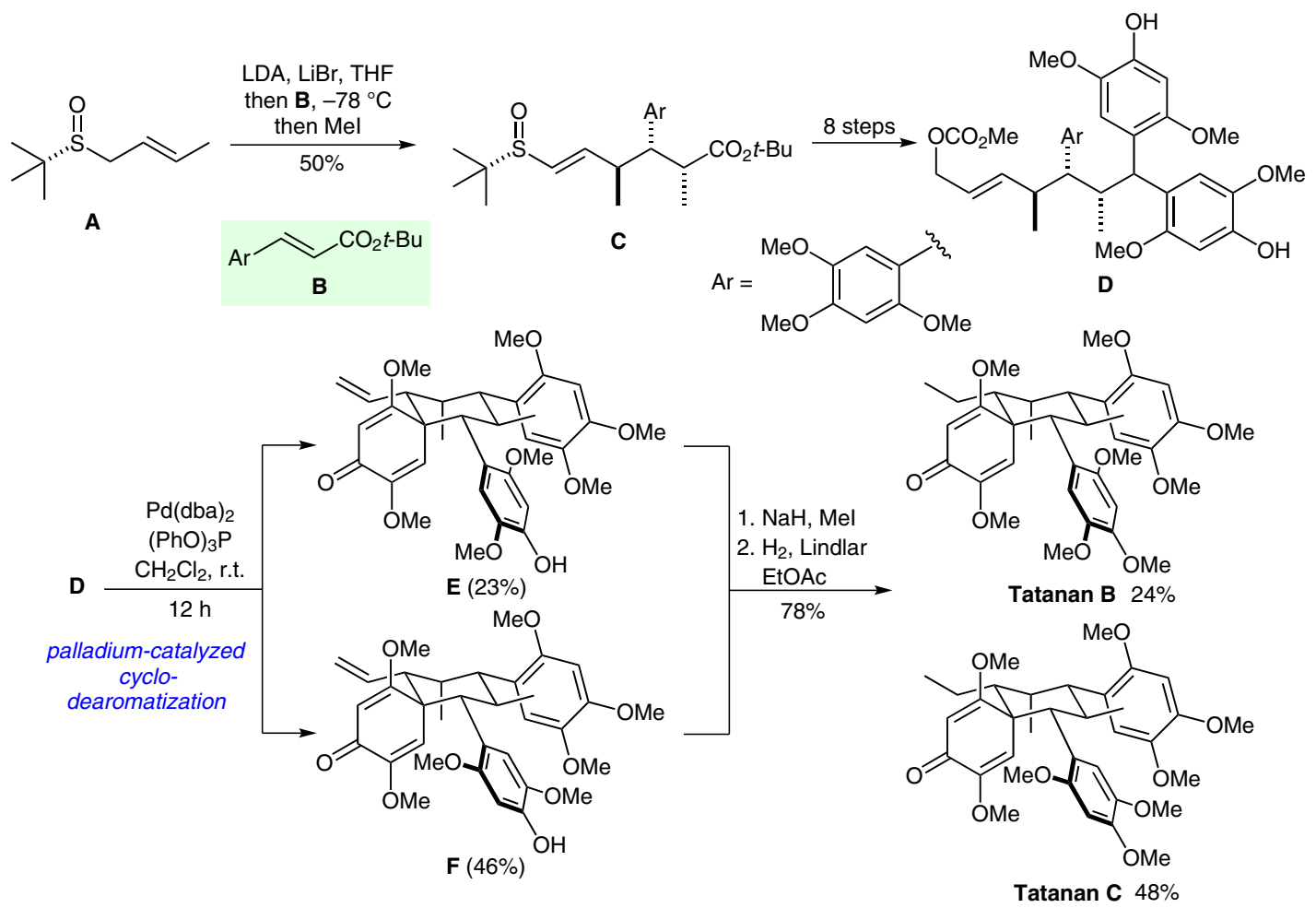

Gategory

Synthesis of Natural

Products and

Potential Drugs

\section{Key words}

tatanans

[3,3]-sigmatropic rearrangements

cyclodearomatization

glucokinase activators

antidiabetic agents
Significance: The tatanans are sesquilignan natural products that have been reported to be powerful glucokinase activators, and thus potential antidiabetic agents (G. Ni et al. J. Org. Chem. 2011, 76, 2056). A. Zakarian, B. G. Miller and coworkers now report the first total syntheses of tatanans A-C and the re-evaluation of their biological activities. In contrast to the previous studies, however, they found that tatanans do not have any glucokinase-activating capabilities.
SYNFACTS Contributors: Erick M. Carreira, Simon Krautwald Synfacts 2013, 9(6), 0579 Published online: 16.05.2013 DOI: 10.1055/s-0033-1338718; Reg-No.: C02813SF
Comment: The synthesis of tatanans B and C commenced with a stereocontrolled conjugate addition-enolate trapping sequence that afforded c. Cleavage of the stereodirecting group was followed by addition of the aryl groups and further elaboration to afford allylic carbonate $\mathbf{D}$. This underwent a remarkably selective palladiumcatalyzed cyclodearomatization to give atropisomers $\mathbf{E}$ and $\mathbf{F}$ in 23 and $46 \%$ yield, respectively, along with another isomer in $15 \%$ yield (not shown). E and $\mathbf{F}$ could then be converted into the natural products by methylation and hydrogenation. The authors also accomplished the synthesis of tatanan A (not shown), an acyclic member of the family of natural products, by a sequence of Claisen rearrangements. 